University for Business and Technology in Kosovo

UBT Knowledge Center

UBT International Conference

2017 UBT International Conference

Oct 27th, 1:20 PM - 2:30 PM

\title{
Analysis of central banks platforms on social networks
}

Goran Bjelobaba

National Bank of Serbia, goran.bjelobaba@nbs.rs

Ana Savic

School of Electrical Engineering and Computer Science Applied Studies, ana.savic@viser.edu.rs

Hana Stefanovic

ComTrade, hana.stefanovic@its.edu.rs

Follow this and additional works at: https://knowledgecenter.ubt-uni.net/conference

Part of the Computer Engineering Commons, and the Computer Sciences Commons

\section{Recommended Citation}

Bjelobaba, Goran; Savic, Ana; and Stefanovic, Hana, "Analysis of central banks platforms on social networks" (2017). UBT International Conference. 81.

https://knowledgecenter.ubt-uni.net/conference/2017/all-events/81

This Event is brought to you for free and open access by the Publication and Journals at UBT Knowledge Center. It has been accepted for inclusion in UBT International Conference by an authorized administrator of UBT Knowledge Center. For more information, please contact knowledge.center@ubt-uni.net. 


\title{
Analysis of central banks platforms on social networks
}

\author{
Goran Bjelobaba ${ }^{1}$, Ana Savic ${ }^{2}$, Hana Stefanovic ${ }^{3}$ \\ 'The National Bank of Serbia, Kralja Petra 12, 11000 Belgrade, Republic of Serbia, \\ ${ }^{2}$ The School of Electrical Engineering and Computer Science Applied Studies, \\ VojvodeStepe 283, 11000 Belgrade, Republic of Serbia, ${ }^{3}$ ComTrade, Information \\ Technology School of Applied Studies, Savskinasip 7, 11070 Belgrade, Republic of \\ Serbia \\ \{goran.bjelobaba@nbs.rs, ana.savic@viser.edu.rs, hana.stefanovic@its.edu.rs \}
}

\begin{abstract}
The paper describes the advantages of using technical and technological achievements through the social networks and their implementation in central banks communication. The paper presents an analysis of the use of the most popular social networks for communication by central banks. Social networking sites today represent the growing importance of daily Internet use, and have become an important factor in our way of communicating. Quickly, accurately and continuously informing the citizens leads to increased confidence which creates a positive attitude towards the central bank that is represented in a good way and communicates with citizens on social networks. The majority of citizens using modern mobile devices spend much time browsing Facebook, Twitter, Instagram and content of some other popular social networks.
\end{abstract}

Keywords: Social networks, the Central bank, communication, Facebook, Twitter

\section{Introduction}

Dialogue with the public and specific target groups moves from offline or "analogue" communication to the digital realm. In this sense, financial sector is no exception. One of the main challenges for central banks is to appropriately, taking into account all the obstacles that communicating with a wider public entails, react in a timely manner and in accordance with the specific target groups, on topics that interest them, the state of the market and the general interest of the public in relation the work of the central bank. By using social networks, central banks are communicating with a wider public, as well as with the target groups, using the interaction that social networks allow.Since communication is an essential element of any policy of central banks, including public expectation management and the impact that Central Bank communication has in financial markets, the content that central banks publish and the manner in which they do it has never been more important, nor more followed.Another thing we can say with certainty is that a greater pro-activity on social networks will gradually abolish the need for conventional telephone customer service centers. Even today, a significant number of central banks following networks activity with great care, such as Twitter or Facebook and consider the opinions of the followers.Objections of users will be available to banks in real time, so the bank will proactively participate in the discussion and influence the preservation of its reputation.In order to effectively use social media, central banks need to understand the use of tools to achieve interaction with the target groups, as well as the way in which they can use feedback received from them for the consideration and preparation of an adequate response.Engaging in social media is certainly not an easy task for central banks in the world. An even greater challenge is for them to build and maintain a successful presence in the online 
environment without its own control. Central Bank is, by definition, a very conservative institution which is prone to complete control. Precisely, the lack of control was a major reason of the hostility central banks have towards social media.

\section{The social networks}

In recent years we have witnessed a real revolution of the Internet as we know it so far. By the early development of social networks, which is the appearance of the first social networking site SixDegrees.com, the concept of Internet search and the Web in general has been focused only on the passive viewing of contents on various Web sites (Danah, 2007). An option of twoway communication with the owners of these web pages was only through the Forum, if those websites had forums. However, before a detailed analysis of social networks, it is necessary to first clarify what constitutes the concept of social networks, regardless of the currently popular social networking sites. The main features of social networks is that they are the most efficient and quickest source of information, they are transparent, always available, free, public, dynamic, multimedia, and provide the necessary two-way communication. It is clear that the Internet has become our everyday life and reality. The fact is that almost anything can be found on the Internet today and that communication has certainly moved to this powerful medium. Even if your target group is slightly older fellow citizens, you should not worry. The time in which the Internet was just a privilege for the young and educated people is long behind us. Online today is everyday life and the basic source of information for citizens. More than $50 \%$ of the population aged over 30 is on the Internet. The fastest growing group of Facebook users was women 55-65 years old (Qualman, 2010: 117).

\section{Central banks in social networks}

In the last five years, there is a growing trend of central banks' presence in social media. Some banks use their presence on social networks to channel traffic to their main site, while others use their presence to spread useful and informative content to different target groups in accessible way.

Central banks' platform in social networks analysis was conducted in order to determine trends in the use of social networks in communication of central banks with media and public. The expansion of social media in the last ten years shows that this area offers enormous opportunities and that they will eventually get bigger. The whole world becomes increasingly interdependent due to interactions that social networks provide. They represent a powerful way to connect central banks with the public. Just a few years ago, central banks may have ignored the importance of social networks without consequences. It is no longer the case. Today, social networks are a challenge for central banks, which must carefully adopt new technologies. The last twelve years, central banks have begun to adopt new technologies in order to reach their target group. Research shows that central banks started using social networks relatively recently and that a very small number of them have an account on social networks for more than five years (European Central Bank, the Bank of England, FED and others).

Sixty central banks have opened accounts on social networks. Of these, 22 banks use Twitter and Facebook, only Twitter in 29 banks, and only Facebook in 9 banks.

Central banks use social networks to increase the support and trust in connecting and discussion with the general public. The performance of central banks on social networks enables promoting plans, results achieved, and educating and informing citizens. 
Twitter is a social network designed for people to leave short messages or "update" the contents of other users. Twitter is one of the most important social networks, which, at the same time, is used the most by central banks. Most central banks use Twitter for dissemination of information. The big challenge for central banks in Twitter is how to build or consolidate confidence, gain authority and be a reliable source for their followers, gain support for future initiatives and current issues of importance. Central banks mostly used Twitter as a popular and specialized channel aimed mainly at journalists and politicians.

Facebook represents the most widespread social network that allows uploading photos, statuses, videos, creating events and many other activities. Social networks are important for central banks because they build their image, promote their work and build a relationship with their followers. Central banks have put the accent on quality information, constantly publishing interesting and educational content to remain connected with their public. Most central banks have their basic message, target group and appropriate content "packed" so that people read it or view it quickly. Such consistency of central banks proved to be the key to winning over the public.

Based on previous research, we came to the conclusion that social networks must be used, i.e. that this communication standard for central banks is attainable, affordable and can no longer be ignored.

\section{Central banks - Twitter}

Central Bank of Nigeria (1.129 tweets, number of followers - 35.9K)

Nigeria provides a useful example of what complications can arise when using social media. The Central Bank of Nigeria in 2013, closed more than 100 false accounts of their governor on social networks. His opponents were accused for wanting to destabilize the country via social media. More than half of central banks working on Twitter / Facebook accounts are in Europe and North America, one-third in South America and Asia, and the rest are divided between Africa and Oceania. Central Reserve Bank of El Salvador (7386 - tweets, the number of followers -4.594) use Twitter to post information on economic growth, trade, and they are not expected to respond to any tweet. The central bank uses Facebook primarily for students and the public, sets "short educational capsules" on the economy and financial concept. One of the innovations is that students have homework titled "attempt and do it now." The central bank plans to expand to YouTube, where it will post educational video clips and interviews with the governor. They find that YouTube will help to attract more people. The Federal Bank of Dallas (tweets - 2922, the number of followers 39.6k) went one step further and opened three Twitter accounts, one for general purposes, other for economic education and the third for business opportunities. They mostly use Twitter for interesting governor's quotes and interviews. An example of the Banque de France shows this can be risky. In 2011, they posted a tweet of the interview their governor, where their governor condemned England to have "a greater deficit in relation to the debt, higher inflation and weaker growth" in relation to France. This interview caused a "great storm" of negative comments. The South African Reserve Banks (SARB) (tweets -1.53 , the number of followers -8.712 ), believes that Twitter is very useful as a tool for two-way communication with the public, and that is the most effective to post new information and redirect users to the site of the central bank. In 2013, SARB released a new series of banknotes to improve the position of governor. Internet team of the Central Bank published the notes on Twitter and Facebook through the "interactive micro-site" designed for mobile devices, so that this announcement raised the consciousness of people who use Twitter and Facebook on the promotion of new banknotes.

In 2012, the Maldives Monetary Authority (MMA) launched a set of video clips titled "Look at economics with the governor" on YouTube and on the internet website. The idea was to explain people various economic issues related to their country in the most realistic way. According to 
the study, one of the leading central banks In Twitter is the Mexican Central Bank (@Banxico) with $386 \mathrm{~K}$ followers, tweeting about 7 times a day, while the Central Bank of France (@banquedefrance) had the biggest number of tweets $12.4 \mathrm{~K}$. It could be concluded that it does not matter how many tweets you post in a day, it is important to find the right followers: influential people, journalists, business partners, employees, customers. Size matters, but is not prevalent. The great challenge is to build trust, gain authority and be a reliable source for followers. There is a table of the analysis of Twitter accounts of central banks (Table 1 and Table 2).

Table 1.Twitter Accounts of Central Banks (Exch. Rates, Rates, Statistics, Followers)

\begin{tabular}{llllll}
\hline CB & Address & Exch. Rates & Rates & Statistics & Followers \\
\hline BE & NBB_BNB_FR NBB_BNB_NL & yes & yes & yes & $\mathbf{1 . 8 2 1 , 2 . 5 2 4}$ \\
DK & nationalbanken & yes & yes & yes & $\mathbf{1 . 4 2 2}$ \\
FI & SoumenPankki & yes & yes & yes & $\mathbf{4 . 6 9 1}$ \\
FR & banquedefrance & yes & yes & yes & $\mathbf{1 7 . 6 K}$ \\
DE & bundesbank & no & no & yes & $\mathbf{1 9 . 2 K}$ \\
IT & UfficioStampaBI & no & no & yes & $\mathbf{1 0 . 8 K}$ \\
LV & LatvijasBanka & yes & yes & yes & $\mathbf{6 . 0 3 6}$ \\
RO & bnr_ro & yes & yes & yes & $\mathbf{1 . 8 4 7}$ \\
SK & nbs_sk & yes & yes & yes & $\mathbf{6 0 6}$ \\
SE & riskbanken & yes & no & yes & $\mathbf{6 . 2 1 8}$ \\
UK & bankofengland & no & yes & yes & $\mathbf{1 8 3 K}$ \\
BH & CBBiH & yes & yes & no & $\mathbf{4 3 7}$ \\
ECB & ecb & yes & yes & yes & $\mathbf{3 3 9 K}$ \\
\hline
\end{tabular}

Table 2.Twitter Accounts of Central Banks (Tweets, English, News, Research Publications, Speeches)

\begin{tabular}{lllllll}
\hline CB & Address & Tweets & English & News & $\begin{array}{l}\text { Research } \\
\text { Publications }\end{array}$ & Speeches \\
& & & & & no \\
BE & NBB_BNB_FR NBB_BNB_NL & $\mathbf{6 . 2 5 1} 6.282$ & yes & yes & yes & no \\
DK & nationalbanken & $\mathbf{4 . 9 5 9}$ & yes & no & no & yes \\
FI & SoumenPankki & $\mathbf{6 . 7 8 7}$ & yes & yes & yes & no \\
FR & banquedefrance & $\mathbf{1 2 . 4 K}$ & yes & no & yes & yes \\
DE & bundesbank & $\mathbf{1 . 7 2 0}$ & yes & yes & no & yes \\
IT & UfficioStampaBI & $\mathbf{1 . 9 4 2}$ & no & yes & yes & no \\
LV & LatvijasBanka & $\mathbf{4 . 1 9 6}$ & no & yes & no & yes \\
RO & bnr_ro & $\mathbf{5 . 7 2 6}$ & yes & no & no & yes \\
SK & nbs_sk & $\mathbf{2 . 8 6 8}$ & no & yes & no & yes \\
SE & riskbanken & $\mathbf{7 6 9}$ & no & yes & no & yes \\
UK & bankofengland & $\mathbf{5 . 7 3 1}$ & yes & yes & yes & no \\
BH & CBBiH & $\mathbf{1 . 2 8 9}$ & yes & no & no & yes \\
ECB & ecb & $\mathbf{7 . 3 6 4}$ & yes & yes & yes & \\
\hline
\end{tabular}

\section{Conclusion}

Social networks present a challenge for central banks, which must carefully adopt the innovations of new technologies. Internet study that was conducted in 2001 by Steve Hanke, professor of applied economics at the "John Hopkins University" and his colleague Michael Morgenstern, showed that 51 central bank does not have a web presentation on the Internet. The 
reason given was the lack of transparency among central banks. The situation in the last fourteen years has significantly changed and the central banks adopt new technologies to reach their target groups. People are no longer looking for the news, the news themselves finds people. Social networks are a great tool for the placement of the desired content in the right way.

According to a study in this paper, around 60 central banks opened accounts on Twitter or Facebook, of these 60 central banks, 22 use Twitter and Facebook, while 29 central banks only use Twitter, and only 9 central banks use Facebook.

Until recently, they were all communicating with the public through the mass media, but now, when information is transmitted in real time, mode of communication has changed. Social networks have taken over television and became the fastest medium. The tone of communication cannot be analyzed and expressed in figures, but it is necessary that is carefully designed and planned. Although we cannot hear the tone, we can read it. On social networks, one should avoid PR releases and official speech tone. Simply, one should behave as the other users behave.

The analysis of the study showed that a growing number of central banks decide to use modern achievements of science and technology in the field of ICT. By creating profiles on the most visited social networks, they reach their target groups in a simple and easy way, providing timely communication

\section{References}

1. Danah, B. (2007). Social Networking Sites: definition, history and scholarship. Retrieved from http://jcmc.indiana.edu/vol13/issue1/boyd.ellison.html.

2. Joksimović, G. (2011). Osnovno o DM. Retrieved from

3. http://www.planeta.org.rs/46/15temabroja2.htm.

4. Qualman, E. (2010). Socialnomics: How social media transforms the way we live and do business. John Wiley \& Sons.

5. Wikipedia, (2016). Društvena mreža. Retrieved from https://sr.wikipedia.org/wiki.

6. Wikipedia, (2016). Social networking service. Retrieved from

7. https://en.wikipedia.org/wiki/Social_networking_service.

8. iSerbia Glas Mladih. Definicija socijalne mreže. Retrieved from

9. http://www.iserbia.rs/novosti/definicija-socijalne-mreze-46/.

10. Hanke, S. H., \& Morgenstern, M. R. (2001). „What's Wrong with Central Bank Websites.“ Central Banking, 11(3).

11. Scott, J. (2012). Social network analysis. Sage.

12. Kwak, H., Lee, C., Park, H., \& Moon, S. (2010, April). What is Twitter, a social network or a news media? In Proceedings of the 19th international conference on World Wide Web (pp. 591-600). ACM.

13. 1Couldry, N. (2012). Media, society, world: Social theory and digital media practice. Polity. 